\title{
Effectiveness of Training on Four Key Aspects to Develop the Interaction between Mother and Children in Early Childhood
}

\author{
Diah Arum Witasari Humani ${ }^{\mathrm{a}}$, Rini Hildayani, ${ }^{\mathrm{b}^{*}}$ and Fenny Hartiani ${ }^{\mathrm{b}}$ \\ ${ }^{a}$ Faculty of Psychology, Universitas Indonesia, Depok, Indonesia, ${ }^{b}$ Department of \\ Developmental Psychology, Faculty of Psychology, Universitas Indonesia, Depok \\ *Corresponding Author: \\ Rini Hildayani \\ Developmental Psychology Department \\ Faculty of Psychology, Universitas Indonesia \\ J1. Lkr. Kampus Raya, Depok, Jawa Barat \\ Indonesia, 16424 \\ Tel.: +62 217270004 \\ E-mail:rhilda@ui.ac.id
}




\title{
Effectiveness of Training on Four Key Aspects to Develop the Interaction between Mother and Children in Early Childhood
}

\begin{abstract}
This research aims to understand the effectiveness of training by playing on four key aspects to develop the interaction between mother and children in early childhood (children aged 3-6 years). The four key aspects of the mother-child interaction are affection, responsiveness, encouragement, and teaching (Roggman et al., 2013). $A B$ design was applied to 11 mother-child dyads as participants. The mothers were provided with 4-day training for a total of 15 hours. The training materials covered the characteristic of children in early childhood, play, and mother-child interaction. Data were analyzed with a combination of qualitative and quantitative methods and t-test statistics. The mother-child interaction was observed and measured using Parenting Interactions with Children: Checklist of Observations Linked to Outcomes (PICCOLO) (Roggman et al., 2013). Statistical results show a significant difference between motherchild interaction scores before and after the training on the four key aspects $(t=-3.339$, $\mathrm{p}=0,008 \leq 0.05)$. Hence, the training on the four key aspects effectively develops the interaction between mother and children in early childhood.
\end{abstract}

Keywords: mother-early childhood children interaction; affection; responsiveness; encouragement; teaching

\section{Introduction}

The low quality of parent-child interaction in Indonesia remains a great concern, as stated by Yohana Yembise, who is the minister of the Women Empowerment and Child Protection (PPPA) Department of the Republic of Indonesia. Minister Yembise also stated that introduction of values, norms, and character formation of children to grow well could not be realized as predicted without the existence of a qualified interaction between parents and children. These conditions become the mutual responsibility of the government and the entire community (Napitupulu, 2016).

Sukiman, the Director of the Family Education Development of the Republic of Indonesia, stated that the community needs to understand that child development is strongly influenced by the interaction of children with their parents. Parents are the leading educators of their children (Wirakusuma, 2017).

The interaction between mother and child is essential in early childhood for optimal growth and development of children (Bayoglu, Unal, Elibol, Karabulut, \& Innocenti, 2013; Horodynski \& Gibbons, 2004; Rogman, Cook, Innocenti, Norman \& Christiansen, 2013). Positive mother-child interaction can support various aspects of child development, including physical, cognitive, and psychosocial aspects.

The physical aspects of a healthy child are strongly influenced by a positive mother-child interaction, which is characterized by mother's responsiveness to child's physical needs (Black \& Aboud, 2011). Black and Aboud (2011) found that a mother or caregiver who responds to cues raised by the child either through voice or body movement will have children with healthy physical growth and normal weight. Another study conducted by Block and Krebs (2005) 
suggested that a positive mother-children interaction can reduce the risk of a child experiencing failure to grow, a condition where child's weight is less than the standard.

Parental support in the form of responsive behavior through interaction by play activities can improve children's cognitive development (Roggman, Boyce, \& Cook, 2009). Roggman, Boyce, and Cook (2009) developed a program that lasted for 3 years to equip parents with skills for interacting with their children through play activities, providing parenting advice, and improving knowledge on child development. At the end of the program, children whose parents received weekly visit showed better attachment security and cognitive development compared with children whose parents did not receive a visit program. The cognitive aspects measured in the study are specifically related to language. Tempel, Wagner, and McNeil (2009) also found that parent-child interaction is associated with language development. The choice of word and the way parents talk to their children must be in tune with the needs of the children to improve their vocabulary and pronunciation.

The psychosocial development of children is characterized by the formation of prosocial behavior in early childhood and is related to the mutual relationship between mother and child (Lindsey, Colwell, Frabutt, Chambers, \& MacKinnon-Lewis, 2008). Mother-child interaction also positively affects the development of empathy for children (McDonald, Baker, \& Messinger, 2016).

Mother-child interaction is defined as giving and receiving cues or feedback reciprocally between mother and child so that a mutual response behavior exists between them (Sumner and Spietz, 1994). The behavior in such interactions should be adjusted to the child's developmental level (Horodynski \& Gibbons, 2004).

Roggman, Cook, Innocenti, Norman, and Christiansen (2013) stated a number of key aspects involved in parent-child interaction. These aspects can be used as reference for parents to identify actions that they can take to support child development. The key aspects are categorized into four domains: affection, responsiveness, encouragement, and teaching. In the affection domain, a mother shows warmth when interacting with her child. Warmth can be observed from mother's excitement or joy when she is involved in activities with her child, physical closeness to her child, and positive expression toward her child. Warmth is reflected through words spoken by a mother. Responsiveness is shown by mother's responsive behavior toward cues demonstrated by the child in terms of body movement, child's emotion, words spoken by the child, child's interest toward something, and behavior displayed by the child. Encouragement is demonstrated by a mother through supportive behavior to her child when exploring new things, making efforts to resolve problems independently, displaying a certain skill, showing initiative to perform an activity, showing curiosity, demonstrating creativity, and doing play activities. In the teaching domain, a mother converses and plays with her child and also provides cognitive stimulation, gives explanations about something, and gives some questions to the child (Roggman, Cook, Innocenti, Norman, \& Christiansen, 2013).

The World Bank survey results in Indonesia (2010) indicated that the interaction between mother and child in daily parenting practices must be improved. The World Bank recommends the importance of learning activities for parents. These activities provide opportunities for parents to 
learn about parenting practices, encourage them to become close to their children, and stimulate all developmental aspects of the children (World Bank, Education Unit, 2010).

In October 2016, an elicitation was conducted on 15 mothers who have with children in early childhood, belong to middle-level socio-economic class, and live in Great Jakarta region. The elicitation was conducted using interview techniques to obtain general information about mother's skill in interacting with her children. The results were analyzed based on four interaction domains introduced by Roggman, Cook, Innocenti, Norman, and Christiansen (2013). The results showed that the participants only demonstrated some of the behaviors required by the four domains of mother-child interaction. However, all mothers stated that mother-child interaction was essential to support child's growth and development. In general, the participants expressed positive attitude toward opportunities to attend training or workshop to improve their knowledge and skills about mother-child interaction.

Given the elicitation results, scholars have widely studied the interaction between mother and child through play activities. Play is a major activity of children and is essential for their development; an activity that provides opportunity for parent to show supporting behavior for child's development is also important (Huisman, Catapano, Moody, \& Gates, 2013; Gagnon, Huelsman, Reichard, Kidder-Ashley, Griggs, Struby \& Bollinger, 2014; Kwon, Bingham, Lewsader, Jeon, \& Elicker, 2013). From children's perspective, Kwon, Bingham, Lewsader, Jeon, and Elicker (2013) stated that through playing, a child would be more involved positively with his parents. Playing can improve children's social interaction with their environment, parents, or peers (Roopnarine \& Davidson, 2015; Gagnon et al., 2014). Meanwhile, parents will show a sense of warmth, sensitivity to children, and appreciation to children's needs in determining their limits of play (Roopnarine and Davidson, 2015).

Considering the importance of the interaction between mother and children in early childhood, the authors determined the effectiveness of training on the four key aspects of interaction to improve mothers' understanding and skills in interacting with their children through play activities. In this study, interaction between mother and child covers four key aspects, namely, affection, responsiveness, encouragement, and teaching.

Several methods for increasing parent-child interaction are Parent-Child Interaction Therapy (PCIT) and Theraplay®. PCIT is applied to children with behavioral disorders (Paste, Wagner, \& McNeil, 2009, Thornberry \& Brestan-knight, 2011), and Theraplay® is a form of psychological intervention for children and families to form and strengthen the relationship between parent and child (Booth and Jernberg, 2010). Both methods involve direct interaction with children, require long implementation time, and can be conducted individually. Considering certain conditions from both types of methods, the researcher decided to develop other training methods based on affection, responsiveness, encouragement, and teaching aspects that were delivered through a training program for mothers.

The main hypothesis indicates that training of the four key aspects of maternal-child interactions can effectively increase the scores of affection, responsiveness, encouragement, and teaching domains as measured using PICCOLO. The measurement will be undertaken in a playing setting. The alternative hypothesis (Ha) states that significant differences exist in the scores of mother- 
child interaction before and after the mother attends the training on the four key aspects. The purpose of this study is to determine the effectiveness of the program implementation on the four key aspects to improve the interaction between mother and child in play situations.

This study is an applied research because the results can be used to develop training programs related to mother-child interaction. This research is also categorized as explanatory type because it aims to explain the influence of one variable to another variable. The answer to the research question is acquired through quantitative and qualitative methods.

\section{Methods}

\section{Participants}

Participants were recruited using accidental sampling technique. The participants consisted of 11 pairs of mother-children (mothers aged 20-40 years and children in early childhood aged 3-6 years), who lived in South Jakarta. Mothers should have an educational background of at least Senior High School and never attended any similar training.

\section{Research Design}

This research is a single-subject design, namely, AB design. The research was designed to determine changes in mother-child interaction scores rated by the participants between before and after the delivery of the training programs. In the early phase of the study, baseline observations were conducted as pre-test. Affection, responsiveness, encouragement, and teaching aspects affecting mother-child interaction through play were observed and assessed using PICCOLO. During the treatment, the mother received training on the four key aspects of mother-child interaction. The mothers practiced the four key aspects (affection, responsiveness, encouragement, and teaching) through role-play activities. These activities were observed by the researcher, and qualitative feedback was given based on the observation. The observation guideline was developed based on PICCOLO. After the treatment phase, the interaction between mothers and their children were observed again. The observation score was recorded as post-test.

\section{Measures}

The measurement tool, namely, Parenting Interaction with Children: Checklist of Observations Linked to Outcomes (PICCOLO), was used to identify the key aspects of parent-child interaction through observation methods (Roggman et al., 2013). PICCOLO has four interaction domains such as affection, responsiveness, encouragement, and teaching. In the four domains, some items can be used as guide to behavioral observation ( 7 items for affection domain, 7 items for responsiveness domain, 7 items for encouragement domain, and 8 items for teaching domain) (Roggman et al., 2013).

PICCOLO measurement reliability was determined based on the scores of the observations independently conducted. The observation results were reviewed jointly by the observers and researchers to obtain and agree on the final score. Roggman et al. (2013) recommended that the percentage of the agreed scores should be at least $75 \%$. The observation result agreed by the observer should be no more than three items with a difference score of 1 point in one domain or only one item that has a difference score of 2 points and one other item with a difference of 1 point in one domain. 
Each item was scored between 0 and 2. Roggman et al. (2013) provided observation guidance and additional notes for each item. Scores for each PICCOLO domain were obtained by summing the scores for each item on one domain. The total score of PICCOLO was determined by summing the scores of each domain. The highest score given by the participants is 58 , and the lowest score is 0 . Table 1 shows examples of items and guidelines for observation.

\section{Procedure}

The study was conducted in four stages, i.e., pre-test, training, post-test, and feedback. The pretest was held on April 29, April 30, and May 1, 2017. Training was conducted on May 2-5, 2017. Post-test was conducted on May 8 and 9, 2017. At the pre-test and post-test, the participants interacted with each other through play activities, which were recorded for 10 minutes.

A pre-test was conducted for 3 consecutive days followed by 4 days of training. The room used for training is quite comfortable. The room has a size of about $36 \mathrm{~m}^{2}$ and is equipped with audio devices, loudspeakers, projectors, projector screens, air conditioners, writing tables, and carpet mats to allow participants to sit down comfortably.

The training materials consist of providing information on characteristics of early childhood development, play in early childhood, and the four key aspects of mother-child interaction (affection, responsiveness, encouragement, and teaching). The training was delivered by lecture method for 6 hours and implemented for 10 hours in the form of observation, simulation, and role play.

Each participant had an opportunity to practice interaction skills during classroom exercises and received qualitative feedback from the facilitator to improve the predicted mother-child interaction behavior. The participants were also given the task of practicing the skills they obtained during each training session at home. The facilitator provided feedback to each participant during the sharing session on the next day.

The total time required for training implementation was 15 hours or 1 hour faster than the initial schedule. On the second and third training days, the time required for skill practice was 30 minutes faster than the initial plan. The training time planned at 08:00 to 12:00 every day was adjusted in the implementation at $08.30-12.30$ on day $1,08.00-12.00$ on day 2 , and $7.30-11.00$ on days 3 and 4 .

\section{Data Analysis}

Data were statistically processed using t-test through the SPSS program. The results of the analysis provided general conclusions of the research conducted. In this study, differences were observed in the interactions of mothers and their children in early childhood before and after training (Gravetter and Forzano, 2012). 


\section{Results}

Table 1 shows the quantitative results of mother-child interaction through playing activities before and after training.

Table 1

Results of mother-child interaction measurements.

\begin{tabular}{lcc}
\multicolumn{1}{c}{ Measurement Result } & Before Training & After Training \\
\hline Average & 30.18 & 40.27 \\
Standard deviation & 11.38 & 5.497 \\
\hline
\end{tabular}

Analysis of the standard deviation results illustrates that before training, the participants showed great variations in mother-child interaction scores, that is, some participants had high, whereas other had low scores. After the training, the mother-child interaction behaviors of the participants showed similarity.

Table 2 presents the measurements based on the four interaction domains.

Table 2

Measurement results of mother-child interaction in each domain.

\begin{tabular}{lcccc} 
& \multicolumn{2}{c}{ Before Training } & \multicolumn{2}{c}{ After Training } \\
\cline { 3 - 5 } \multicolumn{1}{c}{ Measurement Result } & Average & Standard Deviation & Average & Standard Deviation \\
\hline Affection & 6.91 & 1.868 & 11.64 & 1.501 \\
Responsiveness & 8.36 & 3.472 & 10.55 & 1.213 \\
Encouragement & 7.82 & 3.488 & 9.64 & 1.433 \\
Teaching & 7.09 & 4.592 & 8.45 & 2.504 \\
\hline
\end{tabular}

Based on the statistical calculations using the SPSS program, the significance value was $t_{\text {interaction }}$ $=-3.339$ and $p=0.008 \leq 0.05$. The values indicate significant differences in the scores of mother-child interactions measured using PICCOLO through mother-child playing activities before and after training on the four key interaction aspects. Thus, the research hypothesis (Ha) is accepted.

Based on analysis of results on each interaction domain, significant differences were found in affection $\left(t_{\text {affection }}=-6.287, \mathrm{p}=0.000 \leq 0.05\right)$ and responsiveness $\left(t_{\text {responsiveness }}=-2.226, \mathrm{p}=\right.$ $0.050 \leq 0.05)$. Meanwhile, no significant difference was observed in encouragement $\left(t_{\text {encouragement }}\right.$ $=-1.892, \mathrm{p}=0.088>0.05)$ and teaching $\left(t_{\text {teaching }}=-1.095, \mathrm{p}=0.299>0.05\right)$.

Demonstrating affection is the most difficult aspect to do by the participants before attending the training. The participants showed very minimal expected behavior on affection during pre-test sessions. More than half of the participants did not even praise their children after they finished doing something. The participants also did not demonstrate positive expression to their child during the interaction.

After attending the training, most participants could show consistent affection-related behaviors, such as speaking in a softer and warmer tone, always taking a sitting position close to the child during play, and participating in play activities selected by the child. Some praise expressions, 
such as "smart" or "wow... great," were told by a few of the mothers to their children after completing or doing a certain task. However, some participants still demonstrated the expected behavior inconsistently or not in a spontaneous way during the interaction.

Most participants could display behavior on responsiveness aspect before training. The behavior was observed when participants commented on the activity that their children was doing, helped the child in preparing toys, followed the child's desire to choose the game, or looked at the child's face when the child says something. Behaviors that were demonstrated by the mother before attending the training were answering child's questions during playing and responding to his feelings when he had difficulty in dealing with his toys.

After the training, almost all participants could demonstrate all expected behaviors on responsiveness aspect spontaneously and consistently throughout the interaction. Mother looked more responsive in reading child's cues (both verbal and non-verbal) expressed during playing.

Before attending the training, most participants could show encouragement behaviors, such as mother giving her child opportunity to choose the toy to play, offering help when the child is facing a problem, or providing verbal support by saying words, such as "go, go" and "try first" or clapping hands when the child managed to arrange the puzzle independently. Few participants had not demonstrated behaviors on encouragement aspect. Some mothers only watched her child doing the coloring activity without saying any single word to express her enthusiasm.

After attending the training, mothers seemed to give more advice to the child and calmly wait for child's response, give the child opportunity to play toys in his or her way, and offer help if the child encountered difficulty. Mothers' enthusiasm toward child's activities was expressed by comments, such as "the color is good" or "what color do you want to choose?" All participants can demonstrate the expected behavior. However, a consistent difference was found in showing the expected behavior.

Before attending the training, most participants can show behaviors on teaching aspects, such as when children pretend to play as a doctor who wants to check his mother. The mother says, "I'm sick, give me some medicine, please." The child who initially pretended to check his mother with a stethoscope then developed his play by taking an injection and pretending to inject his mother's arm and then gave medicine to his mother.

After the training, most participants can bring up almost all expected behavior. Examples of behaviors that arise are when the child pretends to call someone, the mother explains "I want to explain how to use this phone. Let's call Dad." Mother showed and explained the way to use the phone step by step to her son.

Concerning homework, the participants demonstrated their commitment to do it. Some participants could give examples of behaviors based on mother-child interaction domain. The homework was completed well by all the participants. The homework provided an opportunity for participants to directly practice the skills gained from the training materials with their children at home. 
The conclusions of this study are stated as follows:

1. The training on the four key aspects of mother-child interaction is significantly effective for developing the interactions between mother and children in early childhood through play activities.

2. The training on the four key aspects is significantly effective for improving mother-child interactions in affection and responsiveness domains but has no significant effect on encouragement and teaching domains.

\section{Discussion}

The training on the four key interaction aspects can effectively develop the interaction between mothers belonging to middle socio-economic level and their children in early childhood. Mother-child interaction is enhanced in all four aspects, namely, affection, responsiveness, encouragement, and teaching.

Affection had initially the lowest average score among other aspects. The average score of affection increased dramatically and became the highest after training. All participants already knew about affection behaviors, but they did not demonstrate the behavior in daily interactions. These participants have their reasons for not showing them publicly, such as unfamiliar gesture, feel embarrassed, or perceived them as unnecessary. After the training, the participants showed behavioral changes, such as mothers becoming more expressive, speaking in a warm tone, and easily expressing praise when interacting with their children.

Responsiveness obtained the highest average score before training. Participants showed the predicted behaviors, such as commenting on activities the child is doing, helping a child to prepare toys, following the child's desire to move, or looking toward the child when the child says something. After attending the training, these behaviors could be shown more consistently during the mother-child interaction. The average score of responsiveness was the second highest after the training. The participants have a high educational background and have widespread knowledge about childcare acquired from various printed or electronic media, such as magazines, newspapers, television, or social media applications (e.g., WhatsApp or Facebook).

The average scores of encouragement and teaching aspects also increased after the mothers underwent training. However, the increase is not as high as those in affection and responsiveness scores. The participants showed improvement in the four aspects of interaction, especially in the affection aspect. The participants who achieved high interaction scores before training consistently showed high scores after the training. The participants who had low interaction score before the training showed impressively high score after the training.

The success of this research is supported by several factors, both internal and external, which affect the participants. The first internal factor is participants' intrinsic motivation. To attend the training, the participants must enroll themselves and fill out an informed consent form to show their willingness to engage in this research. The researcher provided brief information to the enrolled participants about research mechanisms and their involvement in the study. Therefore, the participants understood their roles during pre-training observation, training implementation, and post-training observation. The participants were committed to join the entire training program. The training implementation is in line with the adult learning model proposed by Laird, 
Naquin, and Holton III (2003); the model states that the principles of adult learning include participants having their own needs or reasons for training, readiness for training, and motivation for learning.

The second internal factor is participants' educational background. Prospective participants are required to have a high school educational background or equivalent. The training was attended by participants, of which more than half of them hold an undergraduate degree. With this educational background, the participants eased to capture and understand the material delivered during the training sessions. Furthermore, the participants easily provided insights from themselves. This condition is in agreement with that in the study of Galasi (2004), who stated that a person with a high level of education needs a faster time to follow a learning program than those with a low level of education.

In addition to internal factors, external factors may affect the success of this research. The first external factor is the method used in training delivery. The training consisted of the combination between theory and practice with a greater proportion for the latter which was $60 \%$. The total length of the training was 16 hoursThe sequence of training materials was prepared by considering the general concept first followed by specific skills. Hence, the participants will gain a firm foundation on early childhood concepts and their developmental aspects. The key aspects of mother-child interaction were then examined through play activities. Training materials with such proportions were incorporated in activities such as observation, role play, and simulation (Laird, Naquin, \& Holton III, 2003). Diverse learning activities in training delivery, such as listening to lectures, watching videos, group discussion, and role playing, will enrich the training experiences of the mother and help them to understand the training content well. This statement is in line with the statement of Silberman and Biech (2015), who indicated that adult learning process will be more effective when it involves visual and auditory learning modalities. Krätzig and Arbuthnott (2006) also explained that everybody has multi-modalities in learning and different situations; as such, training delivery strategy involving vision, hearing, and kinesthetic will provide an opportunity for participants to learn according to their way.

The second external factor is the provision of homework in the form of "afternoon playing opportunity." The researcher assigned participants to do their homework at the end of the first, second, and third day of training. The homework was given to provide an opportunity for the participants to directly apply their learned skills with their child at home. Providing homework also allowed the participants to be able to practice newly acquired training materials immediately at home.

The third external factor concerns with the fact that children who participated in the study are mostly the youngest in their family. Most mothers felt the need to give more attention and quality time to the younger child because his or her older sibling is considered as more independent than the younger one. Price (2008) stated that the amount of quality time between parent-child tends to decline with age. Mothers become more involved in interactions with a younger sibling. Thus, she has greater time and opportunity to practice the behaviors expected in mother-child interactions. 
This study also has some limitations that may be improved in subsequent research. The first limitation is related to the observation schedule after the training. The observation was conducted 2 or 3 days after the last day of the training. This condition may lead to the high interaction score because the participants still remember well the lessons learned from the training sessions. The results of the observations may be different if the post-training observation is conducted in longer time lags, for example, 1 month after the training.

The second limitation is related to the absence of structured evaluation of the homework. The evaluation was conducted by the researcher during the training sessions. The researcher evaluated the participants by noting their behavioral changes in mother-child interaction based on what the participants told. The researcher did not have a recording of mother-child interactions that occurred during the afternoon play duties. Thus, feedback given to the participants may not be accurate because it is based on notes.

The other limitation is related to the number of co-facilitators involved in the training implementation. During the simulation session, the facilitator observed each group in turn. A group will be observed at the beginning of the simulation, so the facilitator can provide on-time feedback when certain things should be corrected. Meanwhile, another group will be observed at the end of the simulation or even when the simulation is over. Providing feedback by the facilitator to participants in the group cannot be conducted immediately.

The research also has limitations regarding training venue. Although the training room is quite convenient in terms of location and facilities, it is not soundproof. At certain hours when children moved on the yard, the noise can disturb the learning process in the training room.

The following suggestions should be considered for further improvement.

a. The addition of two co-facilitators will be beneficial to perform observation especially during simulation session on days 2 and 3 of training. Thus, every single group has a chance to be observed from the very beginning of the simulation and receive immediate feedback when certain things should be corrected regarding the expected behavior.

b. The evaluations for monitoring the development of mother-child interaction skills should be systematically developed. The "afternoon playing activities" as homework should be recorded so that both participants and researchers will have accurate evidence to observe changes occurring in the interaction. Based on the recording, researchers can also provide accurate feedback to each participant according to the behavior list from the four key aspects of mother-child interaction.

c. If post-training observation is conducted longer than 2 or 3 days after training implementation, then a monitoring system should be developed as part of training follow-up. The monitoring system can provide information about the interactions practiced by the participants at home.

d. The training room should be selected or arranged to be ideal so that the participants do not experience disturbances that may reduce their concentration during training implementation. 


\section{References}

Bank Dunia (2010). Potret Perkembangan anak usia dini di Indonesia. Unit Pendidikan Kantor Bank Dunia, Jakarta. Retrieved from http://datatopics.worldbank.org/hnp/files/edstats/IDNbr10b.pdf.

Bayoglu, B., Unal, O., Elibol, F., Karabulut, E., Innocenti, M.S. (2013). Turkish validation of the piccolo (parenting interaction with children: checklist of observations linked to outcome). Infant Mental Health Journal. Vol. 34. No. 4. P. 330-338.

Black, M. M., \& Aboud, F. E. (2011). Responsive feeding is embedded in a theoretical framework of responsive Parenting1-3. The Journal of Nutrition, 141(3), 490-4. Retrieved from https://search.proquest.com/docview/855819561? accountid=17242.

Block, R.W., \& Krebs, N.F. (2005). Failure to thrive as a manifestation of child neglect. Pediatrics, Vol. 116 No. 5. Retrieved from http://pediatrics.aappublications.org/content/pediatrics/116/5/1234.full.pdf.

Booth, P. B, \& Jernberg, A. M. (2010). Theraplay - Helping parents and children build better relationships through attachment-based play (3rd ed). CA: Jossey-Bass.

Cook, G.A. \& Roggman, L.A. (2013). Technical report - Piccolo user's guide. Retrieved from http://archive.brookespublishing.com/documents/PICCOLO-technical-appendix.pdf.

Gagnon, S. G., Huelsman, T. J., Reichard, A. E., Kidder-ashley, P., Griggs, M. S., Struby, J., \& Bollinger, J. (2014). Help me play! parental behaviors, child temperament, and preschool peer play. Journal of Child and Family Studies, 23(5), 872-884. doi: http://dx.doi.org/10.1007/s10826-013-9743-0

Galasi, P. (2004). Job-training of Hungarian higher-education graduates. Society and Economy, 26(1), 105-125. doi: http://dx.doi.org/10.1556/SocEc.26.2004.1.4.

Gravetter, F. J. \& Forzano, L. B. (2012). Research methods for the behavioral science (4th ed.). Belmont, CA.: Wodsworth Cengage Learning.

Horodynski, M. A., \& Gibbons, C. (2004). Rural low-income mothers' interactions with their young children. Pediatric Nursing, 30(4), 299-306. Retrieved from http://search.proquest.com/docview/199527074?accountid=17242.

Huisman, S., Catapano, S., Moody, A. K., \& Gates, L. K. (2013). Families' perception on play in the early childhood setting. Journal of Psychological and Educational Research, 21(1), 28-48. Retrieved from http://search.proquest.com/docview/1404746730?accountid=17242.

Krätzig, G. P., \& Arbuthnott, K. D. (2006). Perceptual learning style and learning proficiency: A test of the hypothesis. Journal of Educational Psychology, 98(1), 238-246. doi: http://dx.doi.org/10.1037/00220663.98.1.238.

Kwon, K., Bingham, G., Lewsader, J., Jeon, H., \& Elicker, J. (2013). Structured task versus free play: The influence of social context on parenting quality, toddlers' engagement with parents and play behaviors, and parenttoddler language use. Child \& Youth Care Forum, 42(3), 207-224. doi: http://dx.doi.org/10.1007/s10566013-9198-X.

Laird, D., Naquin, S. S., \& Holton III, E. F. (2003). Approaches to training and development. (3rd Ed.). Cambridge, MA: Parseus Publishing.

Lindsey, E. W., Colwell, M. J., Frabutt, J. M., Chambers, J. C., \& MacKinnon-Lewis, C. (2008). Mother-child dyadic synchrony in european american and african american families during early adolescence: Relations with self-esteem and prosocial behavior. Merrill - Palmer Quarterly, 54(3), 289-315. Retrieved from http://search.proquest.com/docview/230097066? accountid=17242.

Napitupulu, R. H. (2016). Menteri Yohana: Kualitas interaksi orang tua anak masih rendah. Jakarta: Antara News. Retrieved from http://www.antaranews.com/berita/603335/menteri-yohana-kualitas-interaksi-orangtuaanak-masih-rendah.

Price, J. (2008). Parent-child quality time. Does birth order matter? The Journal of Human Resources, XLIII.1. Retrieved from http://jhr.uwpress.org/content/43/1/240.full.pdf+html.

Roggman, L. A., Boyce, L.K., \& Cook, G.A. (2009). Keeping kids on track: impacts of parenting - focused early head start program on attachment security and cognitive development. Early Education and Development. Vol. 20 (6). P. 920-941. Doi: 10.1080/10409280903118416.

Roggman, L. A., \& Cardia, N. (2016). Home visitation program - Preventing violence and promoting healthy early child development. Switzerland: Springer International Publishing.

Roggman, L.A., Cook, G.A., Innocenti, M.S., Norman, V.J., \& Christiansen, K.C., \& Anderson, S. (2013). Parenting interactions with children: Checklist of observations linked to outcome (PICCOLO) user's guide. Baltimore, London, Sydney: Paul H Brookers Publishers. 
Roggman, L.A., Cook, G.A., Innocenti, M.S., Norman, V.J., \& Christiansen, K.C (2013). Parenting interactions with children: Checklist of observations linked to outcome (PICCOLO) in diverse ethnic groups. Infant Mental Health Journal. Vol. 34. No. 4. P. 290-306. Doi: 10.1002/imhj.21389

Roopnarine, J. L., \& Davidson, K. L. (2015). Parent-child play across cultures: Advancing play research. American Journal of Play, $7(2), \quad 228-252 . \quad$ Retrieved from http://search.proquest.com/docview/1661719777? accountid=17242.

Silberman, M., \& Biech, E. (2015). Active training: A handbook of techniques, design, case examples, and tips. New Jersey: John Willey \& Sons, Inc.

Sumner, G., \& Spietz, A. (1994). NCAST caregiver/parent-child interaction feeding manual. Seattle, WA: NCAST Publications, University of Washington School of Nursing.

Tempel, A. B., Wagner, S. M., \& McNeil, C. B. (2009). Parent-child interaction therapy and language facilitation: The role of parent-training on language development. The Journal of Speech and Language Pathology Applied Behavior Analysis, 3(2-3), 216-232. Retrieved from http://search.proquest.com/docview/1644176043? accountid=17242.

Thornberry, T., \& Brestan-knight, E. (2011). Analyzing the utility of dyadic parent-child interaction coding system (DPICS) warm-up segments. Journal of Psychopathology and Behavioral Assessment, 33(2), 187-195. doi: http://dx.doi.org/10.1007/s10862-011-9229-6.

Wirakusuma, K. Y. (2017). Pola interaksi orang tua pengaruhi perkembangan anak. Jakarta: Metrotvnews.com. Retrieved from http://m.metrotvnews.com/welcome-page/news/VNnz2rAN-pola-interaksi-orang-tuapengaruhi-perkembangan-anak 